\title{
Editorial
}

\section{Media and Doctor-Patient Relationship}

\author{
KHAN ABUL KALAM AZAD ${ }^{1}$
}

Doctors are in a unique position of respect and power in the society. Hippocrates suggested that doctors may influence patients' health. Trust is the main bondage between a doctor and patient. Most complaints about doctors are related to issues of communication, not clinical competency. Patients want doctors who can skillfully diagnose and treat their sicknesses as well as to communicate with them effectively. Effective doctor-patient communication is a central clinical function in building a therapeutic doctor-patient relationship, which is the heart and art of medicine. ${ }^{1}$

Doctor's communication and interpersonal skills encompass the ability to gather information in order to facilitate accurate diagnosis, counsel appropriately, give therapeutic instructions, and establish caring relationships with patients. ${ }^{2}$

The three main goals of current doctor-patient communication are creating a good interpersonal relationship, facilitating exchange of information, and including patients in decision making. ${ }^{3}$ There are many barriers to good communication in the doctor-patient relationship, including patients' anxiety and fear, doctors' burden of work, fear of litigation, fear of physical or verbal abuse, and unrealistic patient expectations. ${ }^{4}$

In many foreign countries doctors of Bangladesh are playing important roles in the health sector by virtue of their quality. Even foreign examiners appreciated the medical education and examination conduction system as well as the service given by doctors through so many obstacles in this country. In spite of attractive offers and opportunities doctors are giving service to the common people of Bangladesh. It is not that they haven't the quality or ability rather it is their affectionate love for the country people and patriotism which makes them do so.

Being human doctors can do mistakes also. Sometimes overloaded number of patients, clumsy and irritable environment, political pressure make them to do misconduct. But it is not worthy to blame the whole doctor society for it. A common scenario is doctors are blamed in spite of not

1. Professor and Head, Department of Medicine, Dhaka Medical College Hospital.

Corresponding author: Dr. Khan Abulkalam Azad, Professor and Head, Department of Medicine, Dhaka Medical College Hospital, Email:profkakazad@gmail.com being directly related to the logistic supports of the hospital service. It is seen many a times that a single mistake is published in the media in a broad manner which makes people misunderstand the whole scenario. A common term mentioned now a days is "wrong treatment." But without considering the clinical scenario, the environment, the available facilities it is injustice to call a doctor's attempt to save a life "wrong treatment" by some non medical persons without giving the alleged opportunity for self-defense or proper judgment on medical ground. Again hardships of the doctors are rarely appreciated by the media. So, most of the time a negative impression is created among the mass about physicians.

Like other professions there are also corruptions in the doctor community. Some physicians may be corrupted indirectly by getting extra benefits from pharmaceutical and diagnostic centres. But their numbers are negligible compared to the doctors who are working for the welfare of mankind. The whole community shouldn't be blamed for some corrupted. Doctors are giving 24 hour service to the public even on vacations. Noble deeds like emergency blood donation to save people, helping the poor with poor fund raising from own pocket always remain behind the light.

It is very common that people compare the health service of foreign private hospitals to our government hospitals. But they don't consider the difference in the facilities, environment, a huge burden of patients, academic workloads other than treating patients. With the advancement of health science number of patients and health consciousness are also rising in Bangladesh. The doctors are also becoming busy with their academic activities, research \& scientific affairs beside the growing burden of the patients. It is a common complaint of the general public that doctors don't give enough time for consultation.

The chasm between journalists and physicians appears mostly to be one of ignorance rather than conflicting interests or malice. But across this divide exist miscommunication, misunderstanding and the potential for misguided messages to the public. No one will dispute the fact that the problems in medicine are vast, from the economic implosion affecting the ability of the profession to fulfill its mission to the limitations of the system to handle all aspects of medical 
care. Few disagree about the crisis of medical errors or the critical need to improve medical training and health care delivery especially for our aging and poor populations. But journalists and physicians working independently or as adversaries will not solve these problems. ${ }^{5}$

Doctors and journalists come together at a crossroads of public health. Journalists can play a key role to potentially improve health outcomes, develop a professional network, increase personal awareness of news and discoveries, motivate patients, and provide health information to the community. But the accuracy and presentation of the information comes into question at times, putting the goals of journalists and physicians in conflict.

At times, the relationship between doctors and journalists resembles a bad marriage, with equal parts dependence and disdain. Neither group seems to understand nor acknowledge the other's roles and responsibilities with cynical attitudestoward one another. Ultimately, the public and patients suffer. ${ }^{5}$

Both communities should understand the other's professional training, education, deadlines, responsibilities, codes of ethics, and internal stresses. While keeping our roles and responsibilities distinct and clear, we must begin to build a bridge over the chasm. Only then, both doctors and medical journalists can truly serve the public and their professions.

\section{References:}

1. Fong Ha J, Anat DS, Longnecker N. Doctor-Patient Communication: A Review. The Ochsner Journal 10:38-43, 2010 .

2. Duffy FD, Gordon GH, Whelan G, et al. Assessing competence in communication and interpersonal skills: the Kalamazoo II report. Acad Med. 2004;79(6):495-507.

3. Bre' dart A, Bouleuc C, Dolbeault S. Doctor-patient communication and satisfaction with care in oncology. CurrOpinOncol. 2005;17(14):351-354. 